\title{
Penyebab Terjadinya Ruptur Perineum pada Persalinan Normal di RSUD Muntilan Kabupaten Magelang
}

\author{
Eka Prawitasari ${ }^{1}$, Anafrin Yugistyowati ${ }^{2}$, Dyah Kartika Sari ${ }^{3}$, \\ 1,2,3 Sekolah Tinggi IImu Kesehatan Alma Ata Yogyakarta \\ Jalan Ringroad Barat Daya No 1 Tamantirto, Kasihan, Bantul, Yogyakarta
}

\begin{abstract}
Abstrak
Ruptur perineum adalah robekan yang terjadi pada perineum sewaktu persalinan yang dapat mengakibatkan komplikasi persalinan dan nifas yang dapat membahayakan ibu. Bahaya dan komplikasi ruptur perineum antara lain adalah perdarahan, hematoma, fistula, dan infeksi. Berdasarkan studi pendahuluan yang dilakukan di RSUD Muntilan Kabupaten Magelang dari persalinan normal bulan November 2013 sampai dengan Juni 2014 didapatkan 612 orang dengan persalinan normal (spontan), sebanyak 243 orang dengan kejadian ruptur perineum dengan mayoritas terjadi pada ibu primipara sebanyak 37 orang (15,22\%), pada jarak kelahiran $>2$ tahun sebanyak 87 orang (35,80\%), pada usia ibu 20-35 tahun sebanyak 46 orang (18,93\%), dan berat bayi lahir 2.500-4.000 gram sebanyak 73 orang (30,04\%). Tujuan penelitian ini adalah untuk mengetahui distribusi frekuensi ruptur perineum pada persalinan normal dan untuk mengetahui hubungan antara ruptur perineum dengan paritas, jarak kelahiran, umur ibu, dan berat badan bayi lahir pada persalinan normal di RSUD Muntilan Kabupaten Magelang tahun 2015. Jenis Penelitian ini adalah observasional analitik dengan metode pendekatan cross sectional. Sampel dalam penelitian ini adalah ibu bersalin spontan di RSUD Muntilan yang berjumlah 41orang. Pengambilan data dilakukan dengan menggunakan checklist. Hasil uji statistik diperoleh hasil hubungan antara ruptur perineum dengan paritas 0,893, jarak kelahiran 0,682, dan umur ibu 0,434, sedangkan pada berat badan bayi lahir 0,000. Kesimpulan pada penelitian ini adalah tidak ada pengaruh antara paritas, jarak kelahiran, dan umur ibu terhadap kejadian ruptur perineum, sedangkan yang berpengaruh dalam kejadian ruptur perineum adalah berat badan bayi lahir.
\end{abstract}

Kata Kunci: ruptur perineum, paritas, berat badan bayi lahir

\section{Factors Affecting Perineal Rupture of Normal Delivery in RSUD Muntilan Magelang District}

\begin{abstract}
Perineal Rupture is a laceration on perineum when delivering a baby. Perineal rupture is one of lacerations on birth canal which can cause complication which is dangerous for mother. The danger and complication of perineal rupture are bleeding, hematoma, fistula, and infection. Based on the baseline study in RSUD Muntilan Magelang District, the number of normal deliveries in November 2013 to June 2014 found 612 people with normal delivery (spontaneous), as many as 243 people with a rupture perineum and the majority occur in women primiparous total of 37 people (15.22\%), at a birth spacing >2 years as many as 87 people (35.80\%), maternal aged 20-35 years as many as 46 people (18.93\%), and 2.500-4.000 grams birth weight as much as 73 people (30.04\%). The purposes of this study were to know the frequency distribution of perineal rupture on normal delivery and to know the relationship between perineal rupture and partum, birth spacing, mothers' age, birth weight on normal delivery in RSUD Muntilan Magelang District of 2015. This study was observational analytics with cross sectional design. The research samples were 41 women of spontaneous vaginal delivery in RSUD Muntilan. The data were collected by using checklist. Based on the statistical test, there were no significant relationship between perineal rupture and partum ( $p$-value $=0.893)$, birth spacing ( $p$-value $=0.682)$, and mothers age ( $p$-value $=0.434)$; while on birth weight there was a significant relationship with the occurrence of rupture perineum ( $p$-value $=0.000$ ). In conclusion, there was no influence between partum, birth spacing, and mothers' age on perineal rupture. In this study, the factor that influences perineal rupture was the birth weight.
\end{abstract}

Keywords: perineal rupture, partum, birth weight

Info Artikel:

Artikel dikirim pada 25 Mei 2015

Artikel diterima pada 25 Mei 2015 


\section{PENDAHULUAN}

Peningkatan kesehatan ibu merupakan salah satu tujuan Millenium Development Goal's (MDG's). Menurut MDGs peningkatan kesehatan ibu yaitu dengan menurunkan Angka Kematian Ibu (AKI) sebesar 3 per 4 kelahiran hidup dari AKI pada tahun 1990 yaitu 450 per 100.000 kelahiran hidup menjadi 102 per 100.000 kelahiran hidup yang ingin dicapai pada tahun 2015. Berdasarkan Survey Demografi Kesehatan Indonesia tahun 2012 AKI di Indonesia 359 per 100.000 kelahiran hidup(1). Jumlah ini meningkat dibandingkan data SDKI tahun 2007 yang besarnya 228 kematian dan masih merupakan kasus yang tertinggi di Asia(2). Sumber lain menurut hasil survey sensus penduduk pada tahun 2010 AKI di Indonesia menjadi lebih rendah yaitu sebesar 259 per 100.000 kelahiran hidup(3). AKI di Jawa Tengah tahun 2012 yaitu 117 per 100.000 kelahiran hidup ada sedikit peningkatan AKI dibandingkan tahun 2011 yaitu 116 per 100.000 kelahiran hidup. Namun demikian kejadian kematian ibu di Kabupaten Magelang mengalami penurunan dari tahun 2010 sebesar 110 per 100.000 kelahiran hidup menjadi 65 per 100.000 kelahiran hidup(4). Penyebab langsung kematian ibu di Indonesia terkait kehamilan dan persalinan adalah perdarahan sebesar $28 \%$, eklampsi sebesar $24 \%$, infeksi sebesar $11 \%$, partus lama sebesar $5 \%$, dan abortus sebesar $5 \%$. Selain itu anemia dan kekurangan energi kronis (KEK) pada ibu hamil juga menjadi penyebab utama pada kematian ibu(5).

Proses kehamilan dan persalinan adalah suatu proses alamiah yang terjadi pada seorang perempuan. Kehamilan dan persalinan merupakan proses yang sangat rentan terhadap terjadinya komplikasi yang dapat membahayakan ibu maupun bayi dan merupakan salah satu penyebab kematian ibu(6). Persalinan adalah suatu proses pengeluaran hasil konsepsi berupa janin dan plasenta dari rahim melalui jalan lahir(6). Pada periode pasca persalinan, sulit untuk menentukan terminologi berdasarkan batasan kala persalinan yang terdiri dari kala I sampai kala IV(7). Pada periode pasca persalinan dapat terjadi berbagai macam komplikasi seperti perdarahan karena atonia uteri, retensio plasenta, dan rupture perineum. Ruptur perineum adalah perlukaan jalan lahir yang terjadi pada saat kelahiran bayi baik menggunakan alat maupun tidak menggunakan alat(8). Ruptur perineum terjadi pada hampir semua persalinan pertama dan tidak jarang juga pada persalinan berikutnya. Ruptur perineum umumnya terjadi di garis tengah dan bisa menjadi luas apabila kepala janin lahir terlalu cepat(5). Ruptur perineum dibagi atas 4 tingkat yaitu derajat I sampai derajat IV(7).
Faktor-faktor yang menyebabkan terjadinya ruptur perineum antara lain faktor ibu yang terdiri dari paritas, jarak kelahiran, cara meneran yang tidak tepat, dan umur ibu. Faktor janin yang terdiri dari berat badan bayi baru lahir dan presentasi. Faktor persalinan pervaginam terdiri dari ekstraksi forceps, ekstraksi vakum, trauma alat dan episiotomi, kemudian faktor penolong persalinan yaitu pimpinan persalinan yang tidak tepat(9).

Berdasarkan studi pendahuluan yang dilakukan di RSUD Muntilan Kabupaten Magelang dari persalinan normal bulan November 2013 sampai dengan Juni 2014 didapatkan 612 orang dengan persalinan normal (spontan), sebanyak 243 orang dengan kejadian ruptur perineum dengan mayoritas terjadi pada ibu primipara sebanyak 37 orang $(15,22 \%)$, pada jarak kelahiran $>2$ tahun sebanyak 87 orang (35,80\%), pada usia ibu 20 35 tahun sebanyak 46 orang $(18,93 \%)$, dan berat bayi lahir 2.500-4.000 gram sebanyak 73 orang (30,04\%). Tingginya kejadian ruptur perineum di RSUD Muntilan dimungkinkan karena penatalaksanaan pimpinan persalinan yang tidak sesuai dengan APN, faktor ibu, dan faktor bayi.

Secara umum penelitian ini bertujuan untuk mengetahui faktor-faktor penyebab terjadinya ruptur perineum pada persalinan normal di RSUD Muntilan Kabupaten Magelang tahun 2014. Secara khusus untuk mengetahui distribusi frekuensi dari kejadian ruptur perineum berdasarkan paritas, jarak kelahiran, berat badan bayi, dan umur ibu, untuk mengetahui hubungan kejadian ruptur perineum dengan paritas, untuk mengetahui hubungan kejadian ruptur perineum dengan jarak kelahiran, untuk mengetahui hubungan kejadian ruptur perineum dengan umur ibu, untuk mengetahui hubungan kejadian ruptur perineum dengan berat badan bayi di RSUD Muntilan.

\section{BAHAN DAN METODE}

Jenis penelitian yang digunakan dalam penelitian ini adalah observasional analitik dengan pendekatan metode cross sectional (potong lintang). Teknik pengambilan sampel adalah dengan menggunakan teknik non random sampling dan cara yang digunakan adalah purposive sampling. Sampel dalam penelitian ini adalah ibu bersalin spontan di RSUD Muntilan yang berjumlah 41 orang. Data yang digunakan dalam penelitian ini adalah data primer yang diperoleh dari observasi langsung pada responden dan data sekunder, yaitu data yang diperoleh dari rekam medik ibu bersalin yang mengalami ruptur perineum di Rumah Sakit Umum Daerah Muntilan Kabupaten Magelang. Pengambilan data dilakukan dengan menggunakan checklist. Variabel dalam 
penelitian ini terdapat dua variabel. Variabel bebasnya (independent) adalah paritas, jarak kehamilan, umur ibu, berat bayi lahir. Variabel terikatnya (dependent) adalah ibu bersalin dengan ruptur perineum di RSUD Muntilan. Analisa yang digunakan dalam penelitian ini adalah analisa univariat yang dilakukan untuk mengetahui distribusi frekuensi, dan analisa bivariat yang digunakan untuk mengetahui apakah terdapat suatu hubungan antara dua variabel.

\section{HASIL DAN BAHASAN}

Ruptur perineum adalah robekan yang terjadi pada perineum sewaktu persalinan(6). Ruptur perineum terjadi pada hampir semua persalinan pertama dan tidak jarang juga pada persalinan berikutnya(7). Terjadinya ruptur perineum disebabkan oleh faktor ibu (paritas, jarak kelahiran dan berat badan bayi), pimpinan persalinan tidak sebagaimana mestinya, riwayat persalinan. Ekstraksi forceps, ekstraksi vakum, trauma alat dan episiotomi(8).

Berdasarkan analisa univariat pada Tabel 1 diketahui bahwa dari 41 responden, ibu bersalin yang mengalami ruptur perineum terbanyak yaitu pada ibu bersalin dengan ruptur perineum derajat 2 sebanyak 24 orang $(58,54 \%)$; sedangkan jumlah terkecil ibu bersalin yang mengalami ruptur perineum yaitu pada derajat 1 sebanyak 8 orang $(19,51 \%)$.

Tabel 1. Distribusi Frekuensi Ruptur Perineum

\begin{tabular}{lcc}
\hline \multicolumn{1}{c}{ Rupture Perineum } & Jumlah & $\%$ \\
\hline Derajat 1 & 8 & 19,51 \\
Derajat 2 & 24 & 58,54 \\
Derajat 3 & 9 & 21,95 \\
Total & 41 & 100,00 \\
\hline
\end{tabular}

Sumber: Data Sekunder Tahun 2015

Tingginya angka kejadian ruptur perineum derajat 2 di RSUD Muntilan adalah disebabkan karena kurangnya komunikasi yang baik antara penolong persalinan dan ibu bersalin, seperti pada saat belum ada pembukaan lengkap ibu sebenarnya tidak dianjurkan untuk mengejan tetapi ibu terus saja mengejan sehingga pada saat waktunya harus mengejan ibu sudah kelelahan sehingga ibu tidak kooperatif saat proses persalinan berlangsung. Selain itu pada saat penelitian ini di lakukan respondennya lebih banyak primipara dan pada umumnya mereka belum mempunyai pengalaman dengan proses kelahiran sebelumnya, belum mengetahui teknik mengejan yang benar, posisi persalinan yang benar dan perineum pada primipara cenderung kaku dan tidak elastis sehingga mudah sekali terjadi ruptur.

\section{Analisis Bivariat}

\section{Hubungan antara Ruptur Perineum dengan Paritas}

Paritas adalah jumlah anak yang pernah dilahirkan oleh ibu, baik yang lahir hidup maupun yang lahir mati dari pasangan suami istri. Pada kehamilan yang terlalu sering maka akan menyebabkan alatalat reproduksi belum pulih dan belum siap untuk menjalani proses persalinan kembali sehingga menyebabkan daerah perineum mudah sekali ruptur. Paritas 2-3 merupakan paritas paling aman ditinjau dari sudut kematian. Primipara mempunyai resiko ruptur lebih tinggi, karena belum pernah mempunyai pengalaman dalam persalinan dibandingkan pada multipara ataupun grande multipara(8).

Tabel 2. Distribusi Frekuensi Hubungan antara Ruptur Perineum dengan Paritas

\begin{tabular}{lcccl}
\hline \multicolumn{1}{c}{ Paritas } & Derajat & Derajat & Derajat & p-value \\
& $\mathbf{1}$ & $\mathbf{2}$ & $\mathbf{3}$ & -var \\
\hline Primipara & 4 & 11 & 4 & 0,893 \\
Multipara & 4 & 10 & 4 & \\
Grande Multipara & 0 & 3 & 1 & \\
Total & 8 & 24 & 9 & \\
\hline
\end{tabular}

Sumber: Data Primer Tahun 2015

Berdasarkan Tabel 2 diketahui bahwa hasil cross tabulasi antara variabel ruptur perineum dengan paritas menunjukan hasil uji statistik chi-square diperoleh nilai $p$-value sebesar 0,893 ( $p>0,05)$ yang berarti tidak terdapat hubungan yang bermakna antara paritas dengan rupture perineum. Hal ini disebabkan tidak selalu ibu dengan paritas sedikit (primipara) mengalami ruptur perineum dan paritas banyak (multipara dan grande multipara) tidak mengalami ruptur perineum, karena setiap ibu mempunyai tingkat keelastisan perineum yang berbeda-beda. Semakin elastis perineum maka kemungkinan tidak akan terjadi ruptur perineum. Pada bulan-bulan terakhir kehamilan akan terjadi peningkatan hormon yang dapat melembutkan jaringan ikat apabila dilakukan pemijatan di area perineum secara rutin. Peningkatan elastisitas perineum akan mencegah terjadinya ruptur perineum maupun episiotomi(10).

\section{Hubungan antara Ruptur Perineum dengan Jarak Kelahiran}

Berdasarkan hasil penelitian bahwa dari dari 28 orang ibu bersalin pada jarak kelahiran $<2$ tahun, jumlah terbanyak ibu bersalin yang mengalami ruptur perineum yaitu pada ibu bersalin dengan ruptur perineum derajat 2 sebanyak 18 orang (43,90\%); sedangkan pada jarak kelahiran $>2$ tahun, jumlah terbanyak ibu bersalin yang mengalami ruptur 
perineum yaitu pada ibu bersalin dengan ruptur perineum derajat 2 sebanyak 6 orang $(14,63)$.

Tabel 3. Distribusi Frekuensi Hubungan antara Ruptur Perineum dengan Jarak Kelahiran

\begin{tabular}{lcccc}
\hline Jarak & Derajat & Derajat & Derajat & p-value \\
Kelahiran & $\mathbf{1}$ & $\mathbf{2}$ & $\mathbf{3}$ & \\
\hline$<2$ tahun & 5 & 18 & 5 & \\
$>2$ tahun & 3 & 6 & 4 & 0,217 \\
Total & 8 & 24 & 9 & \\
\hline
\end{tabular}

Sumber: Data Primer Tahun 2015

Berdasarkan Tabel 3 di atas diketahui bahwa hasil cross tabulasi antara variabel ruptur perineum dengan paritas menunjukan hasil uji statistik chisquare diperoleh nilai $p$-value sebesar $0,217(p>0,05)$ yang berarti tidak terdapat hubungan yang bermakna antara jarak kelahiran dengan ruptur perineum. Namun dengan perawatan luka perineum, menjaga kebersihan hygene dengan baik, dan melakukan senam kegel yang dilakukan pada pasca persalinan dapat memperbaiki dan memulihkan tonus otot perineum sehingga akan membantu mempercepat kesembuhan luka perineum. Selain itu, dengan melakukan perineum massage pada area bekas luka jahitan perineum juga akan membuat perineum lebih elastis dan dapat mengurangi risiko rupture perineum saat persalinan(10).

\section{Hubungan antara Ruptur Perineum dengan Umur Ibu}

Hasil penelitian menunjukkan bahwa ibu bersalin yang mengalami ruptur perineum derajat 1 sebanyak 1 orang dengan umur ibu $<20$ tahun $(2,43 \%)$ dan 7 orang ibu bersalin dengan umur ibu 20-35 tahun (17,07\%). Pada ibu bersalin yang mengalami derajat 2 sebanyak 1 orang dengan umur ibu $<20$ tahun $(2,43 \%), 17$ orang ibu bersalin dengan umur ibu $20-35$ tahun $(41,46 \%)$, dan 6 orang ibu bersalin dengan umur ibu $>35$ tahun $(14,63 \%)$; sedangkan pada ibu bersalin yang mengalami derajat 3 sebanyak 1 orang dengan umur ibu $<20$ tahun (2,43\%), 5 orang ibu bersalin dengan umur ibu 20-35 tahun $(12,19 \%)$, dan 3 orang ibu bersalin dengan umur ibu $>35$ tahun $(7,31 \%)$.

Berdasarkan Tabel 4 diketahui bahwa hasil cross tabulasi antara variabel ruptur perineum dengan paritas menunjukan hasil uji statistik chi-square diperoleh nilai $p$-value sebesar $0,434(p>0,05)$ yang berarti tidak terdapat hubungan yang bermakna antara ruptur perineum dengan umur ibu. Menurut Mochtar, meskipun umur ibu normal apabila tidak berolahraga dan rajin bersenggama dapat mengalami ruptur perineum(6). Kelenturan jalan lahir dapat berkurang apabila calon ibu kurang berolahraga atau genetalianya sering terkena infeksi. Infeksi akan
Tabel 4. Distribusi Frekuensi Hubungan antara Ruptur Perineum dengan Umur Ibu

\begin{tabular}{|c|c|c|c|c|}
\hline $\begin{array}{c}\text { Umur } \\
\text { Ibu }\end{array}$ & $\begin{array}{c}\text { Derajat } \\
1\end{array}$ & $\begin{array}{c}\text { Derajat } \\
2\end{array}$ & $\begin{array}{c}\text { Derajat } \\
3\end{array}$ & $p$-value \\
\hline$<20$ tahun & 1 & 1 & 1 & \multirow{4}{*}{0,434} \\
\hline 20-35 tahun & 7 & 17 & 5 & \\
\hline$>35$ tahun & 0 & 6 & 3 & \\
\hline Total & 8 & 24 & 9 & \\
\hline
\end{tabular}

Sumber: Data Primer Tahun 2015

mempengaruhi jaringan ikat dan otot di bagian bawah dan membuat kelenturannya hilang (karena infeksi dapat membuat jalan lahir menjadi kaku). Hal ini juga dipengaruhi oleh perineum yang sempit dan elastisitas perineum sehingga akan mudah terjadinya robekan jalan lahir, oleh karena itu bayi yang mempunyai lingkar kepala maksimal tidak dapat melewatinya sehingga dapat menyebabkan ruptur perineum.

\section{Hubungan antara Ruptur Perineum dengan Berat Badan Bayi Lahir}

Hasil penelitian ini menunjukkan bahwa ibu bersalin yang mengalami ruptur perineum derajat 1 sebanyak 8 orang ibu yang melahirkan dengan berat badan bayi lahir $2.500-4.000$ gram (19,51\%). Pada ibu bersalin yang mengalami ruptur perineum derajat 2 sebanyak 7 orang ibu yang melahirkan dengan berat badan bayi lahir $<2.500$ gram $(17,07 \%), 16$ orang ibu bersalin yang melahirkan dengan berat badan bayi lahir 2.500-4.000 gram (39,02\%), dan 1 orang ibu bersalin yang melahirkan dengan berat badan bayi lahir $>4.000$ gram (2,43\%); sedangkan pada ibu bersalin yang mengalami ruptur perineum derajat 3 sebanyak 3 orang ibu yang melahirkan dengan berat badan bayi lahir 2.500-4.000 gram (7,31\%) dan 6 orang ibu yang melahirkan dengan berat badan bayi lahir $>4.000$ gram (14,63\%).

Berdasarkan Tabel 5 berikut ini diketahui bahwa hasil cross tabulasi antara variabel ruptur perineum dengan paritas menunjukan hasil uji statistik chisquare diperoleh nilai $p$-value sebesar $0,000(p>0,05)$ yang berarti terdapat hubungan yang bermakna antara berat badan bayi lahir dengan ruptur perineum.

Tabel 5. Distribusi Frekuensi Ruptur Perineum dengan Berat Badan Bayi Lahir

\begin{tabular}{lcccc}
\hline \multicolumn{1}{c}{$\begin{array}{c}\text { Berat } \\
\text { Bayi (gram) }\end{array}$} & $\begin{array}{c}\text { Derajat } \\
\mathbf{1}\end{array}$ & $\begin{array}{c}\text { Derajat } \\
\mathbf{2}\end{array}$ & $\begin{array}{c}\text { Derajat } \\
\mathbf{3}\end{array}$ & $\boldsymbol{p}$-value \\
\hline$<2.500$ & 0 & 7 & 0 & \multirow{2}{*}{0,000} \\
$2.500-4.000$ & 8 & 16 & 3 & \\
$>4.000$ & 0 & 1 & 6 & \\
Total & 8 & 24 & 9 & \\
\hline
\end{tabular}

Sumber: Data Primer Tahun 2015 
Hasil penelitian yang didapatkan menunjukkan kesesuaian dengan teori yang menyatakan bahwa semakin besar berat badan bayi yang dilahirkan akan meningkatkan resiko terjadinya ruptur perineum, karena perineum tidak cukup kuat menahan proses kelahiran bayi dengan berat badan bayi lahir yang besar sering terjadi ruptur perineum(11).

\section{SIMPULAN DAN SARAN}

Pada penilitian ini didapatkan distribusi frekuensi ruptur perineum pada ibu bersalin di RSUD Muntilan pada bulan Februari tahun 2015 yaitu pada derajat 2 sebanyak 24 orang $(58,4 \%)$ sedangkan ibu bersalin yang mengalami rupture perineum derajat 3 sebanyak 9 orang $(21,95 \%)$, dan ibu bersalin yang mengalami rupture perineum derajat 1 sebanyak 8 orang $(19,51 \%)$. Dalam penelitian ini tidak terdapat hubungan yang bermakna antara ruptur perineum dengan paritas, jarak kelahiran, dan umur ibu, dan terdapat hubungan yang bermakna antara ruptur perineum dengan berat badan bayi lahir.

Diharapkan untuk menurunkan angka kejadian rupture perineum dari tahun ke tahun yang terus meningkat maka sebaiknya pasien dan keluarga diberikan penyuluhan pentingnya ANC sedini mungkin.

\section{RUJUKAN}

1. SDKI. Angka Kematian Ibu. Jakarta: Survei Demografi dan Kesehatan Indonesia; 2012.

2. SDKI. Angka Kematian Ibu Melahirkan [internet]. 2007 [cited 2015 Maret 3]. Available from: http://www.menegpp.go.id/aplikasidata/ index.php?option=com_docman\&t ask $=$ doc_ download\&gid=290\&ltemid=61.

3. Badan Pusat Statistik. Estimasi Fertilitas, Mortalitas dan Migrasi Hasil Sensus Penduduk Tahun 2010. Badan Pusat Statistik: Jakarta; 2010.

4. Dinkes Jawa Tengah. Profil Kesehatan Provinsi Jawa Tengah [internet]. 2012 [cited 2014 November 30]. Available from: https://www. google.co.id/search?q=www.dinkes+jateng. go.id\&oq=www.dinkes-jateng.go.id.

5. Depkes RI. Profil Kesehatan Indonesia [internet]. 2008 [cited 2014 November 30]. Available from: https://www.google.co.id/search?q=www.depkes. go.id\&oq=www. depkes.go.id.

6. Mochtar. Sinopsis Obstetri Fisiologi Patologi. 3rd ed. Jakarta: ECG; 2010.

7. Prawirohardjo S. IImu Kandungan. Jakarta: Yayasan Bina Pustaka Sarwono Prawirohardjo; 2008.

8. Wiknjosastro. IImu Bedah Kebidanan. 1st ed. Jakarta: Yayasan Bina Pustaka Sarwono Prawirohardjo; 2008.

9. Nasution N. Faktor-faktor yang Berhubungan dengan Terjadinya Ruptur Perineum pada Ibu Bersalin Di RSU Dr.Pirngadi Medan Periode Januari-Desember 2007: J kesehatan. 2011;I(2).

10. Aprilia, Yessi. Hipnostetri: Rileks, Nyaman, dan Aman Saat Hamil \& Melahirkan. Jakarta: Gagas Media; 2010.

11. Varney H. Buku Ajar Asuhan Kebidanan. Jakarta: EGC; 2010. 